\title{
Two Sides of a Coin: The Dual Roles of Chitinase 3-Like 1 in Idiopathic Pulmonary Fibrosis
}

\author{
Christina S. Turn • Narasaiah Kolliputi
}

Received: 21 August 2014/Accepted: 23 September 2014/Published online: 1 October 2014

(c) Springer Science+Business Media New York 2014

Idiopathic pulmonary fibrosis (IPF), a progressive, fatal lung disease, primarily affects patients over 50 years of age. These individuals present with symptoms of respiratory failure, including worsening dyspnea, cough, and decreased exercise tolerance. Additionally, these patients often present with bilateral, inspiratory crackles, and demonstrate finger clubbing [1]. With the progression of idiopathic pulmonary fibrosis, patients lose the lung elasticity and normal alveolar architecture that permit normal respiration, which results in their eventual respiratory failure and death. In fact, between 50 and $80 \%$ of patients afflicted with idiopathic pulmonary fibrosis die within 5 years of their initial diagnoses [2,3]. Additionally, annual mortality attributable to IPF is higher than the mortality caused by certain cancers, like melanoma or brain cancers [4]. While risk factors like cigarette smoking have been associated with idiopathic pulmonary fibrosis, none have consistently presented with IPF to suggest a causative effect $[5,6]$. The pathogenesis of IPF is still a subject of much investigation. Recent research has shown that the development of IPF involves two sequential phases: injury with apoptosis, followed by remodeling and an extensive fibrotic response. However, because the lesions within an IPF lung are temporally heterogeneous, the pathogenesis and regulation of this disease largely remain unexplained.

A recent publication by Zhou et al. may have shed some light on the potential mechanisms for the cycles of injury and tissue remodeling that occurs in idiopathic pulmonary

C. S. Turn · N. Kolliputi $(\bowtie)$

Division of Allergy and Immunology, Department of Internal Medicine, Morsani College of Medicine, University of South Florida, 12901 Bruce B. Downs Blvd., MDC 19, Tampa, FL 33612, USA

e-mail: nkollipu@health.usf.edu fibrosis [7]. They examined the role of chitinase 3-like 1 (CHI3L1), a chitinase-like protein whose expression pattern is altered in several inflammatory diseases, in patients with and in murine models of IPF. At present, CHI3L1 is known to drive inflammatory pathways while preventing apoptosis and inducing fibrosis through molecules like TGF- $\beta$ [8-10]. Now, Zhou et al. have proposed a significantly more complex role for CHI3L1 in the development and progression of idiopathic pulmonary fibrosis that could even suggest potential treatments for this devastating disease (Fig. 1).

The authors first conducted several studies involving lung and blood samples from IPF patients to characterize the role of CHI3L1 in this disease. When lung biopsies from patients with IPF were compared to those of patients with lung metastases, both the proportion of and overall number of epithelial cells and macrophages expressing CHI3L1 were significantly increased. This data indicates that an elevation in this chitinase-like protein is associated with IPF in general.

Afterward, Zhou et al. quantified CHI3L1 in IPF patients who presented with varying degrees of severity. This prospective cohort study found that, although CHI3L1 was elevated in the blood of all patients with IPF when compared to age-matched controls, patients with a more progressive form of the disease exhibited the highest levels of CHI3L1. However, when the CHI3L1 levels in patients suffering from acute exacerbations of IPF were quantified, CHI3L1 appeared to be quite low. Additionally, these patients, who were undergoing diffuse alveolar damage, demonstrated more epithelial and inflammatory cell apoptosis.

Based upon these results and their previous work, the authors reasoned that an increase in CHI3L1 may prevent tissue injury by increasing the activity of $\mathrm{M} 2$, or so-called 


\section{Injury Phase}

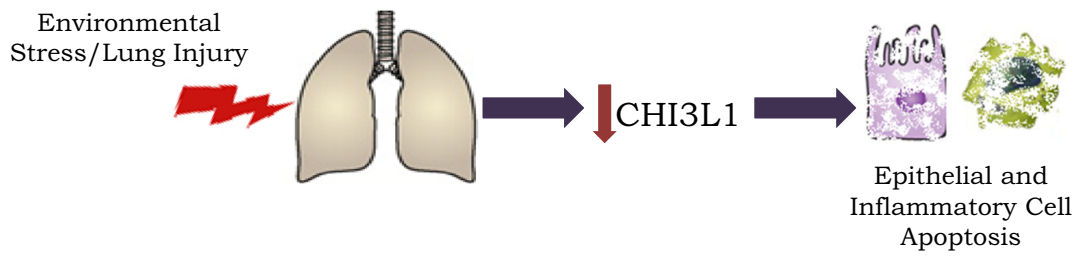

\section{Fibrotic Phase}

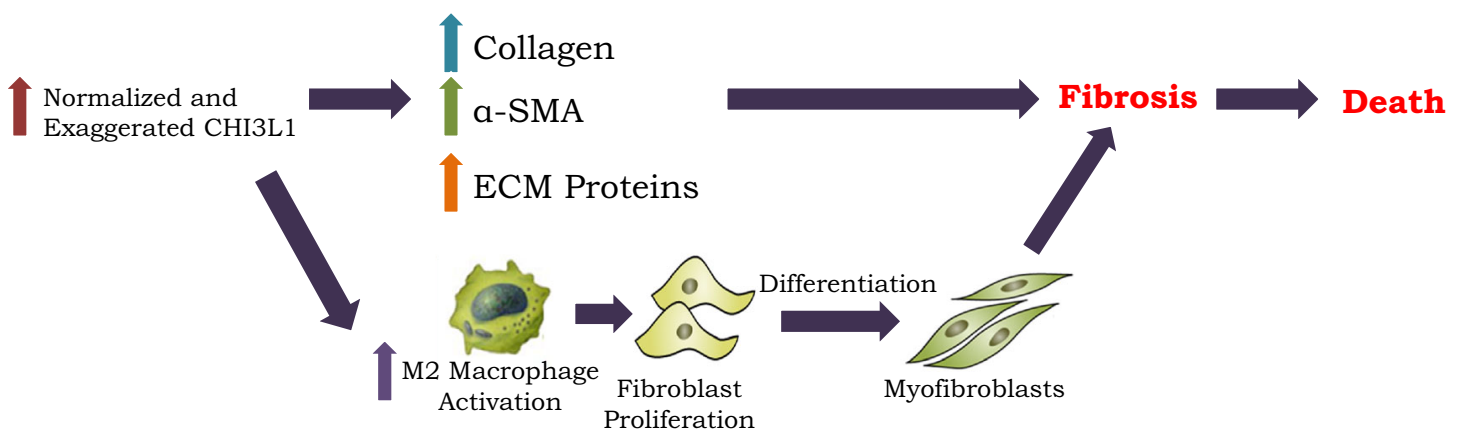

Fig. 1 Changes in CHI3L1 expression throughout the development of idiopathic pulmonary fibrosis

alternatively activated, macrophages, which are characterized in part by the expression of CD206 on their cell surfaces. In fact, a cellular population that also expressed CD206 was detected in large quantities in both the blood and lung tissue of patients with IPF, and patients with the poorest prognosis presented with the greatest abundance of these cells. Of note, when these $\mathrm{CD} 14^{\mathrm{hi}}, \mathrm{CD}_{206}{ }^{+}$cells were placed on a three-dimensional, decellularized scaffold, they dramatically stimulated the proliferation of fibroblasts. Taken together, these results demonstrate that an increase in CHI3L1 stimulates the accumulation of CD206 cells in the bloodstream and lungs, which then increases the density of fibroblasts in the tissue.

To more fully understand the role of CHI3L1 in the development of IPF, the authors conducted several experiments in bleomycin-exposed mice, a classical model for idiopathic pulmonary fibrosis. When first treated with bleomycin, these mice exhibited a marked, transient decrease in both CHI3L1 mRNA expression and CHI3L1 levels in bronchoalveolar lavage (BAL) fluid. However, over time, the CHI3L1 levels normalized and continued to increase as the mice recovered from the bleomycin-induced injury. The researchers used YKL-40 transgenic mice to selectively express CHI3L1 at certain points during the injury and fibrosis phases. When CHI3L1 expression was activated before the bleomycin treatment and was turned off fourteen days after the insult, the mice demonstrated hallmarks of fibrosis and inflammatory cell infiltrates. However, when CHI3L1 was only expressed during the initial injury phase, the mice did not develop as much collagen deposition, and their lung tissue demonstrated significantly lower levels of epithelial cell apoptosis.

On the other hand, when the CHI3L1 expression was limited to the fibroproliferative repair phase of injury and recovery, the mice demonstrated significantly higher amounts of collagen deposition, as well as elevated extracellular matrix protein and $\alpha$-SMA gene expression, markers for fibrosis. The presence of $\alpha$-SMA indicated that the mouse fibroblasts had converted into myofibroblasts, a hallmark of idiopathic pulmonary fibrosis. Additionally, these mice had a higher mortality rate than those from other experiments. When the mice did not express any CHI3L1 during their recovery from the bleomycin exposure, the mice showed an increase in pulmonary epithelial cell apoptosis, inflammatory cell accumulation in the lungs, and death. However, these mice did not show any alteration in collagen deposition. When these same mice had CHI3L1 activated during the initial injury phase, fibrosis development decreases dramatically.

Based on bone marrow chimeras of null and CHI3L1expressing mice, bone marrow-derived cells (BMDCs) are not required to produce $\mathrm{CHI} 3 \mathrm{~L} 1$ for normal, reparative fibrosis. However, when BMDCs do secrete CHI3L1, more soluble collagen can be detected, which indicates that these cells enhance structural cells' normal fibrotic response to injury. When these BMDCs were examined in greater detail, they were found to express CD206 and other M2 macrophage markers.

When macrophages from a fibrotic lung were grown together with fibroblasts, the fibroblasts both increased 
their proliferation rates and survived for longer periods. However, these macrophages did not induce the expression of $\alpha$-SMA. Interestingly, when exposed to human, recombinant CHI3L1, both fibroblast proliferation and $\alpha$-SMA expression increased, which suggested myofibroblast transformation.

Overall, Zhou et al. have begun to delineate some of the complicated roles of CHI3L1 in the development and maintenance of idiopathic pulmonary fibrosis. Their results show that the regulation of CHI3L1 must be carefully balanced. Too little expression during the injury phase can result in subsequent, extensive fibrosis, while too much expression in the fibrosis phase drives excessive deposition of collagen and other extracellular matrix proteins. Although many questions about CHI3L1 and its role in IPF remain, this research makes significant progress toward enhancing our clinical knowledge of IPF and toward possibly finding a treatment for acute exacerbations of IPF.

Acknowledgments NK was funded by the American Heart Association National Scientist Development Grant 09SDG2260957 and National Institutes of Health R01 HL105932 and the Joy McCann Culverhouse Endowment to the Division of Allergy and Immunology. CST was supported by National Institutes of Health Grant T35HL007489.

Conflict of interest None.

\section{References}

1. Raghu G, Collard HR, Egan JJ, Martinez FJ, Behr J, Brown KK, Colby TV, Cordier JF, Flaherty KR, Lasky JA, Lynch DA, Ryu JH, Swigris JJ, Wells AU, Ancochea J, Bouros D, Carvalho C, Costabel U, Ebina M, Hansell DM, Johkoh T, Kim DS, King TE, Kondoh Y, Myers J, Müller NL, Nicholson AG, Richeldi L,
Selman M, Dudden RF, Griss BS, Protzko SL, Schünemann HJ, Fibrosis AEJACoIP (2011) An official ATS/ERS/JRS/ALAT statement: idiopathic pulmonary fibrosis: evidence-based guidelines for diagnosis and management. Am J Respir Crit Care Med 183:788-824

2. Bjoraker JA, Ryu JH, Edwin MK, Myers JL, Tazelaar HD, Schroeder DR, Offord KP (1998) Prognostic significance of histopathologic subsets in idiopathic pulmonary fibrosis. Am J Respir Crit Care Med 157:199-203

3. Selman M, King TE, Pardo A (2011) Idiopathic pulmonary fibrosis. Lancet 378:1949-1961

4. Jemal A, Siegel R, Ward E, Murray T, Xu J, Thun MJ (2007) Cancer statistics, 2007. CA Cancer J Clin 57:43-66

5. Camelo A, Dunmore R, Sleeman MA, Clarke DL (2014) The epithelium in idiopathic pulmonary fibrosis: breaking the barrier. Front Pharmacol 4:173

6. King C, Nathan SD (2013) Identification and treatment of comorbidities in idiopathic pulmonary fibrosis and other fibrotic lung diseases. Curr Opin Pulm Med 19:466-473

7. Zhou Y, Peng H, Sun H, Peng X, Tang C, Gan Y, Chen X, Mathur A, Hu B, Slade MD, Montgomery RR, Shaw AC, Homer RJ, White ES, Lee CM, Moore MW, Gulati M, Geun Lee C, Elias JA, Herzog EL (2014) Chitinase 3-like 1 suppresses injury and promotes fibroproliferative responses in Mammalian lung fibrosis. Sci Transl Med 6:240ra276

8. Lee CG, Hartl D, Lee GR, Koller B, Matsuura H, Da Silva CA, Sohn MH, Cohn L, Homer RJ, Kozhich AA, Humbles A, Kearley J, Coyle A, Chupp G, Reed J, Flavell RA, Elias JA (2009) Role of breast regression protein 39 (BRP-39)/chitinase 3-like-1 in Th2 and IL-13-induced tissue responses and apoptosis. J Exp Med 206:1149-1166

9. Matsuura H, Hartl D, Kang MJ, Dela Cruz CS, Koller B, Chupp GL, Homer RJ, Zhou Y, Cho WK, Elias JA, Lee CG (2011) Role of breast regression protein-39 in the pathogenesis of cigarette smoke-induced inflammation and emphysema. Am J Respir Cell Mol Biol 44:777-786

10. Sohn MH, Kang MJ, Matsuura H, Bhandari V, Chen NY, Lee CG, Elias JA (2010) The chitinase-like proteins breast regression protein-39 and YKL-40 regulate hyperoxia-induced acute lung injury. Am J Respir Crit Care Med 182:918-928 